\title{
Species distribution modelling in low-interaction environments: Insights from a terrestrial Antarctic system
}

\author{
JENNIFER E. LEE, ${ }^{1,2 \star}$ PETER C. LE ROUX, ${ }^{1 \dagger}$ K. IAN MEIKLEJOHN ${ }^{3}$ AND \\ STEVEN L. CHOWN ${ }^{1}$ \\ ${ }^{1}$ Centre for Invasion Biology, Department of Botany and Zoology, Stellenbosch University, Private Bag \\ X1, Matieland 7602, South Africa (Email: jlee@sun.ac.za), ${ }^{2}$ British Antarctic Survey, Natural \\ Environment Research Council, Cambridge, UK; and ${ }^{3}$ Department of Geography, Rhodes University, \\ Grahamstown, South Africa
}

\begin{abstract}
It is widely acknowledged that in the terrestrial Antarctic, interspecific interactions are typically unimportant in determining species distributions and community structure. Therefore, correlative models should prove useful for predicting current and future spatial variation in species abundance patterns. However, this idea has not been formally tested, and the utility of such models, which have shown value for understanding the distribution of diversity elsewhere, for investigating biodiversity patterns in Antarctica remains unclear. Here we make a start at such tests by using generalized linear and simultaneous autoregressive models to demonstrate that simple environmental variables and information about the spatial structure of the environment can explain more than $90 \%$ of the variation in the abundance of Maudheimia wilsoni (Oribatida; Maudheimiidae), a representative of one of the most significant groups of Antarctic terrestrial arthropods, the mites. We show that a single environmental variable, maximum soil moisture content, can account for as much as $80 \%$ of the variance in the abundance of the mite, and that linear models with only a few environmental and spatial terms can be used to forecast the species abundance at the landscape scale. Given ongoing calls for better understanding of the distribution of Antarctic diversity and its likely future change, this initial test indicates that such modelling procedures, and more sophisticated versions thereof, hold much promise for the region and should be tested for other taxa with different life forms and habitat requirements.
\end{abstract}

Key words: Antarctic, arthropod, biodiversity, soil moisture, species distribution model.

\section{INTRODUCTION}

Understanding the factors underlying the global distribution of biodiversity and its heterogeneity has long been one of biology's most compelling objectives (Gaston 2000). Until recently, the prediction of spatial and temporal patterns in biodiversity has perhaps been less frequently emphasized. Forecasting the outcomes of even relatively simple population dynamics (May 1986), let alone those of complex ecological interactions (Lawton 1999) and of evolution (Dennett 1996), has proven difficult. However, with ongoing anthropogenic modification of the biosphere and the resulting negative effects on biodiversity (Millennium Ecosystem Assessment 2005), interest in forecasting biodiversity patterns has grown rapidly. Several recent advances have provided approaches that can be used to predict future patterns in biodiversity (Thuiller

${ }^{\star}$ Corresponding author.

tPresent address: Department of Geosciences and Geography, University of Helsinki, PO Box 64, FI-00014, Finland.

Accepted for publication March 2012.

(C) 2012 The Authors

Austral Ecology (C) 2012 Ecological Society of Australia
2007; Chown et al. 2010; Lavergne et al. 2010). Among these, species distribution models of various kinds (reviewed in Elith \& Leathwick 2009; Kearney \& Porter 2009) are proving especially useful. They offer a readily implementable means to forecast species ranges (and in some instances abundances) and therefore provide insight into where interventions might be necessary to secure the conservation of particular species and/or assemblages, or to limit the impacts of biological invasions (Thuiller et al. 2005). Moreover, when scaled up, similar approaches, based on organism-environment relationships, provide means of forecasting likely future higher-level patterns in biodiversity (Woodward \& Kelly 2008).

Nonetheless, species distribution modelling approaches have been criticized for a variety of reasons. These criticisms largely deal with the extent to which the models fail to distinguish the various factors determining species current ranges, so making predictions unreliable under conditions without contemporary analogues (Pearson \& Dawson 2003; Soberón 2007; Chown \& Gaston 2008; Kearney \& Porter 2009). For example, correlative models cannot distinguish 
whether a response represents a direct causal relationship, a mutual response to a collinear factor, or an effect mediated by a biotic interaction, so making forecasts problematic (Kearney \& Porter 2009). In consequence, it has been suggested that a combination of approaches should be used for forecasting, though recognizing that mechanistic models often require substantial information gathered from specific experiments on the species concerned (see Porter et al. 2000 but also Kearney et al. 2009). However, the use of data intensive-models is problematic in regions that are undergoing rapid environmental change and where better understanding of species distribution is urgently required to facilitate conservation planning.

In areas where biotic interactions play a relatively insignificant role, correlative models may prove useful for modelling both current and future distributions, especially where information on likely dispersal limitation (see Soberón 2007) can be gained from spatial patterning in the species abundance structure or from life history information. Although a reduced role for biotic interactions seems unlikely in many situations (though see, e.g. Kozak \& Wiens 2007 who assume implicitly that physiological tolerances can be gauged directly from distribution range information), one area where these assumptions are plausible is in abiotically stressful environments such as in polar regions and deserts, for which much interest exists in modelling future changes in species ranges (Millennium Ecosystem Assessment 2005). This is true particularly for the terrestrial Antarctic, where species richness is typically low, distributions are patchy (Sohlenius \& Boström 2008) and interspecific interactions (predation and competition) are thought to be relatively unimportant in determining species abundance and community structure (Janetschek 1970; Hogg et al. 2006). Moreover, considerable significance has been attached to understanding how species are likely to respond to rapidly changing climates in the region (Turner et al. 2009), and what the consequences thereof will be both for the efficacy of the system of specially protected areas on the continent (Hughes \& Convey 2010) and for the establishment and spread of non-indigenous species (Frenot et al. 2005).

Here we provide an example of how relatively simple modelling techniques can be used to describe a high proportion of the variation in abundance of Maudheimia wilsoni Dalenius \& Wilson 1958 (Oribatida; Maudheimiidae) at a site in western Dronning Maud Land, continental Antarctica. This species is representative of one of the most significant groups of Antarctic terrestrial arthropods (the mites; see Pugh 1993), and is in consequence an appropriate species for examining the efficacy of this distribution modelling approach for other arthropod taxa in similar environments. We show that straightforward models (generalized linear (GLZ) models and simultaneous autoregressive (SAR) models) based on soil moisture and temperature and information about the spatial structure of the environment can explain more than $90 \%$ of the variation in the abundance of $M$. wilsoni. Furthermore, these models can be used to forecast abundances at the landscape scale. Although other taxa may vary in the shape of their response curves, we suggest that for low interaction environments these models are worthy of further investigation especially where there is a conservation imperative to rapidly assess the distribution of species, and detailed mechanistic information is not available.

\section{METHODS}

\section{Study site}

This study was conducted over a 48 -h period in January 2010 on the Jutulsessen nunatak, Western Dronning Maud Land (DML) close to the Norwegian Antarctic Research Expedition station Troll $\left(72^{\circ} 00^{\prime} \mathrm{S}, 002^{\circ} 32^{\prime} \mathrm{E}\right)$. The mean annual air temperature at Jutulsessen at $1 \mathrm{~m}$ above ground level is $-14.3^{\circ} \mathrm{C}$ (SD 7.8, K.I. Meiklejohn, unpubl. data, 2010). Precipitation data for Jutulsessen are not available, but in the Western DML region precipitation is typically between 55 and $81 \mathrm{~mm}$ per year, falling exclusively as snow (Reijmer \& van den Broeke 2001). Although liquid water availability is primarily driven by microclimate rather than by macroclimate temperature, liquid water is scarce, occurring only during the short austral summer when microclimate temperatures are high enough to cause brief periods of melt.

The study site comprised a large area of non-sorted polygons, that is, landform features formed by repeated soil freezing (Fig. 1). These polygons are formed by cracks in the permafrost resulting from the contraction of the ground during freeze events (Ballantyne 2007). The cracks may be thickened and extended downward into the underlying permafrost incrementally through melt-water filling the cracks and then freezing (Ballantyne 2007; Murton 2007). The microtopography of these features affects processes, such as snow accumulation and melt water run-off, that may be important to biota due to their impact on soil moisture availability (French \& Guglielmin 2000). At Jutulsessen, these polygons range from 5 to $30 \mathrm{~m}$ in diameter with cracks at the periphery of polygons measuring $0.1-0.5 \mathrm{~m}$ wide and $0.1-0.3 \mathrm{~m}$ deep (Fig. 1, K.I. Meiklejohn, unpubl. data, 2010).

\section{Sampling protocol}

For sampling, polygon cracks and centres were considered discrete habitats. At 20, non-adjacent polygons (see Appendix S1 in Supporting Information for satellite image of study site), crack and centre habitats were searched for $15 \mathrm{~min}$ each and all intact M. wilsoni (exoskeletons were excluded) were counted by a single observer (JEL) and collected for subsequent identification verification. Mites are typically about $0.1 \mathrm{~mm}$ and because of their brown colouration 


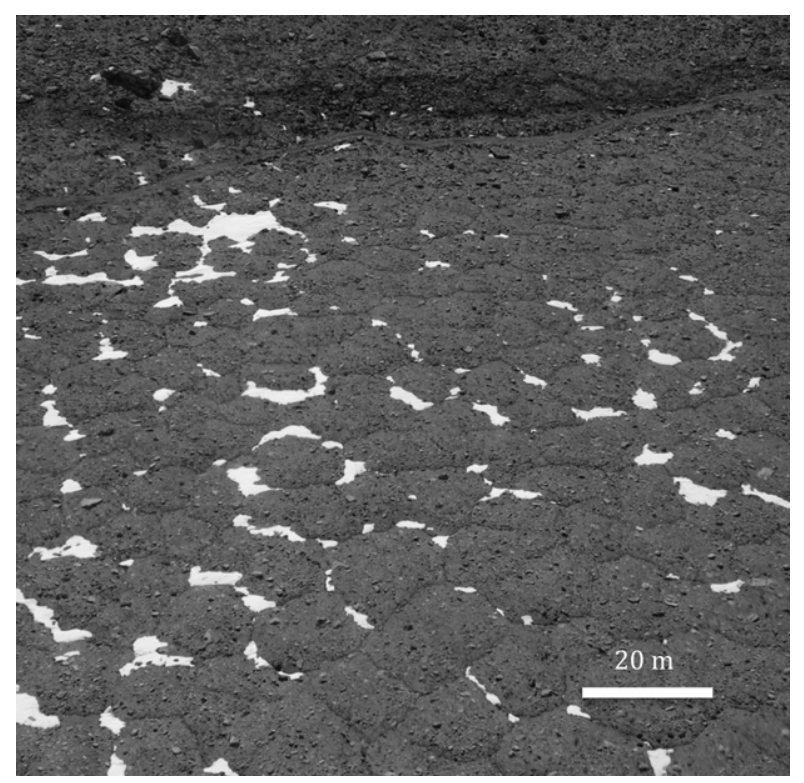

Fig. 1. Polygons on the Jutulsessen nunatak in Western Dronning Maud Land. Note: photograph taken from air; scale only accurate at point of measurement.

require practise to detect in the field. Nonetheless, after training such detection is relatively straightforward, and because sampling effort was equal across crack and centre habitats the relative abundance data are considered accurate and comparable.

Surface and sub-surface $(2-3 \mathrm{~cm}$ below the surface) temperatures were highly variable within polygons, and were therefore measured at 10 points across each crack and centre habitat using a ST642 General Purpose Hybrid Infra-Red Thermometer (AWR Smith Process Instrumentation, Pinegowrie, Gauteng, South Africa). Soil moisture content was also measured at 10 points within each polygon's centre and crack, using a WRS-WD14 moisture meter (AWR Smith Process Instrumentation, Pinegowrie, Gauteng, South Africa). Five soil samples were taken from the site and used to calibrate the moisture meter for the specific substrate (see Appendix S2 in Supporting Information for the method and calibration graph). Abiotic data were collected simultaneously with the abundance data. Mean, minimum and maximum soil moisture and temperature values for each polygon's crack and centre were calculated and included in analysis. The maximum diameter of each sampled polygon was also measured (hereafter: axis length).

\section{Statistical analysis}

The univariate relationships between $M$. wilsoni abundance and the environmental parameters were first examined using Kruskal-Wallis tests (Zar 1984; Quinn \& Keough 2002), before implementing GLZ models (assuming a Poisson distribution and using a log link function) to perform best subsets regression with all permutations of explanatory variables considered. Models were examined for collinearity between explanatory variables, and models with strong col- linearity were excluded (i.e. maximum variance inflation factor across all explanatory variables exceeding a value of 3). The remaining models were then ranked by Akaike Information Criterion values (AIC), with the lowest AIC value indicating the best-fit model.

Analyses were subsequently repeated following a spatially explicit approach, using SAR models (Dormann et al. 2007; Kissling \& Carl 2008). The SAR models consider the response at a given location to be a function of the conditions at that location and the response at neighbouring locations, using a spatial weights matrix to describe the proximity of locations (Kissling \& Carl 2008). As a result, SAR models perform well for describing local spatial patterns (Beale et al. 2010). The SAR error model was implemented, and models were analysed using three weighting styles (binary, row-standardization and variance stabilization) and five neighbourhood distances (75, 150, 300, 450, $600 \mathrm{~m}$; following recommendations of Kissling \& Carl 2008). All permutations of the explanatory variables were modelled, highly collinear models excluded, and the remaining models ranked by AIC. Analyses were conducted using the glm, gvif and errorsarlm functions (in the stats, faraway and spdep libraries, respectively) in $\mathrm{R}$ v2.11.1 ( $\mathrm{R}$ Development Core Team 2010). All analyses were repeated using just the data from the centre habitats, and just the data from the crack habitats.

The predictive ability of the best GLZ and SAR models was assessed using repeated random sub-sampling validation. The models were trained on a randomly selected set of $75 \%$ of the data (training dataset), and then applied to the remaining data (testing dataset). The observed $M$. wilsoni abundance was compared with the predicted abundance in both the training and testing datasets, and the coefficient of determination $\left(R^{2}\right.$; for GLZ models, pseudo- $R^{2}$; for SAR models) calculated for both the training and testing datasets (Kissling \& Carl 2008). This procedure was repeated 1000 times, and the mean $R^{2}$ or pseudo- $R^{2}$ values compared for the training and testing datasets.

\section{RESULTS}

Mite abundance was significantly higher in the polygon cracks (mean $\pm \mathrm{SD}=9.8 \pm 3.7$ ) than the polygon centres $\left(2.6 \pm 1.5 ; \quad K W-H_{1,40}=28.45\right.$, $P<0.001)$. Polygon cracks had a significantly higher mean soil moisture than the centre $\left(\mathrm{KW}-\mathrm{H}_{1,40}=27.84\right.$, $P<0.001$; Fig. 2a) although there was no standing water at any of the sampling locations. Sub-surface temperature was significantly lower in cracks than in centres (KW-H $\mathrm{H}_{1,40}=4.33, P=0.037$; Fig. $\left.2 b\right)$. Surface temperature did not differ significantly between the two habitats $\left(\mathrm{KW}-\mathrm{H}_{1,40}=0.211, P=0.64\right.$; Fig. $2 \mathrm{c}$ ). Surface and sub-surface temperatures were highly variable in both crack and centre environments (Fig. 2b,c) over the short period over which the data were collected which is typical for Antarctic environments (Bockheim \& Hall 2002).

The best-fit non-spatial model (GLZ) for all data (crack and centre habitats combined) included terms 
(a)
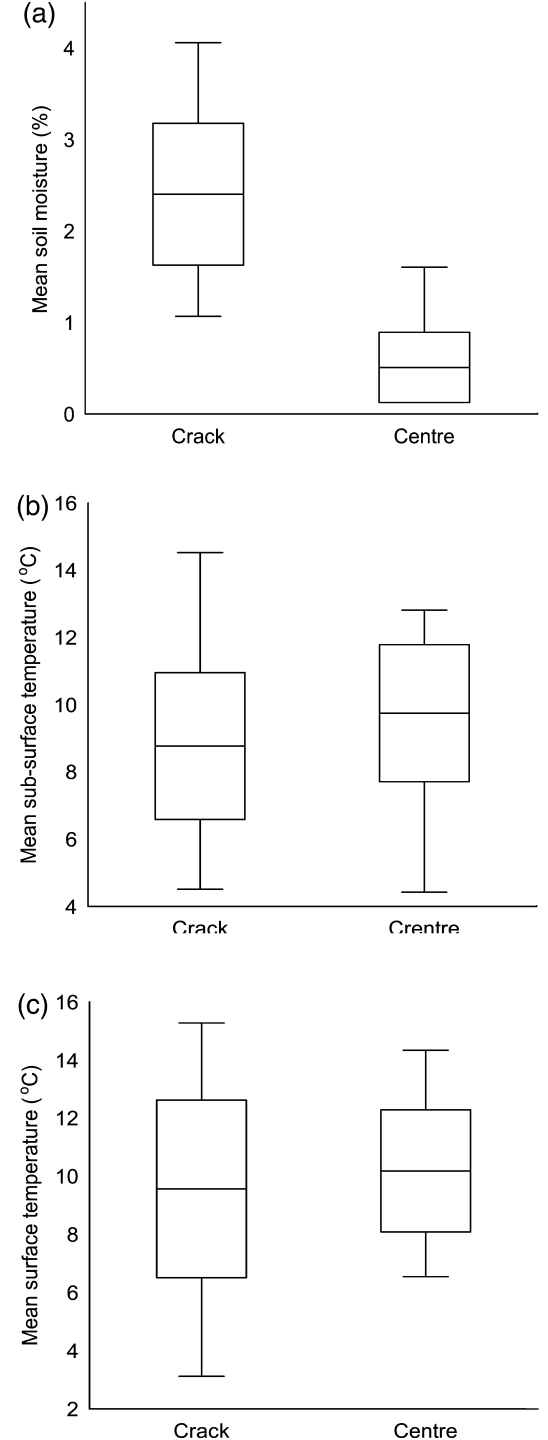
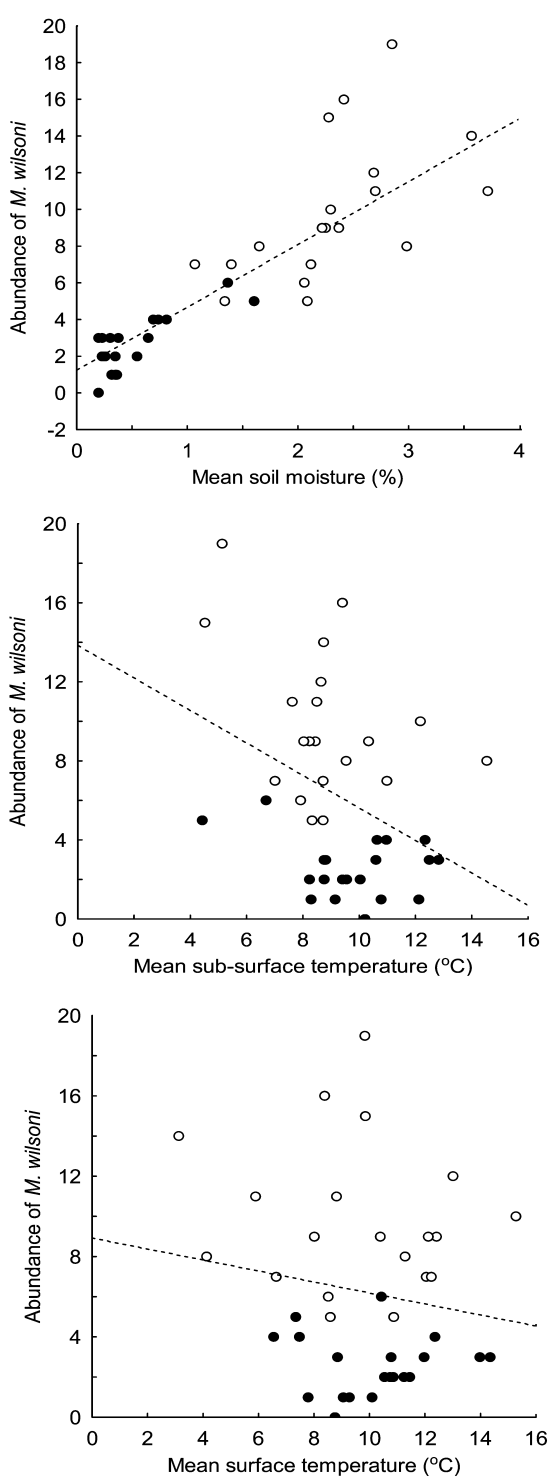

Fig. 2. (a) Mean soil moisture, (b) mean sub-surface temperature and (c) mean surface temperature in polygon crack and centre habitats. Boxes represent mean $\pm 1 \mathrm{SD}$, whiskers representing the minimum-maximum range. For scatterplots, open symbols represent polygon crack habitats, closed symbols represent centre habitats. Dashed lines represent the best linear fit for each univariate relationship and are presented for ease of interpretation only.

for axis length, mean surface temperature, minimum sub-surface temperature, minimum soil moisture and maximum soil moisture (Table 1). When abundance data from cracks were analysed, the best-fit model included the presence of snow, minimum surface temperature, minimum soil moisture and maximum soil moisture (Table 1). Analysing centre data, the model terms included axis length, mean surface temperature, mean sub-surface temperature, minimum sub-surface temperature and maximum soil moisture (Table 1). Applying SAR models to all the data, the best-fit model was similar to the GLZ model, except that axis length was excluded and the presence of snow included. The best-fit SAR models for crack and centre data separately did not differ from the corresponding GLZ models, although the contribution of some terms changed from significant to nonsignificant (Table 1; outputs from all models available on request from authors). The best-fit models showed good predictive ability, with a mean decline of only $2.63 \%$ and $4.65 \%$ in $R^{2}$ values of the best-fit SAR and GLM when comparing the training and test datasets respectively (Table 2).

When single variables were used as predictors in GLZ and SAR models, sub-surface and surface temperature parameters proved to be poor predictors with $R^{2}<0.37$ for all models (Table 3 ). However, moisture parameters explained a much higher proportion of the 
Table 1. Best-fit spatially non-explicit generalized linear (GLZ) models and spatially explicit simultaneous autoregressive (SAR) models for all data, and for crack and centre habitat data separately

\begin{tabular}{|c|c|c|c|c|c|c|c|c|}
\hline Model & $\begin{array}{c}\text { Adj } R^{2} / \\
\text { Pseudo- } R^{2}\end{array}$ & $\begin{array}{l}\text { Likelihood } \\
\text { ratio test } \\
\text { statistic }\end{array}$ & $P$ & $\begin{array}{l}\text { Neighbourhood } \\
\text { weighting } \\
\text { method }\end{array}$ & $\begin{array}{l}\text { Neighbourhood } \\
\text { distance }(\mathrm{m})\end{array}$ & Term & Coefficient & $P$ \\
\hline GLZ - all data & 0.83 & 76.49 & $\star \star \star$ & NA & NA & $\begin{array}{l}\text { Intercept } \\
\text { Axis } \\
\text { Mean TS } \\
\text { Min TSS } \\
\text { Min SM } \\
\text { Max SM }\end{array}$ & $\begin{array}{r}1.307 \\
-0.054 \\
0.096 \\
-0.064 \\
24.787 \\
47.527\end{array}$ & $\begin{array}{l}\star \\
\star \\
\star\end{array}$ \\
\hline SAR - all data & 0.92 & 84.67 & $\star \star \star$ & Binary & 450 & $\begin{array}{l}\text { Intercept } \\
\text { Snow } \\
\text { Mean TS } \\
\text { Min TSS } \\
\text { Min SM } \\
\text { Max SM }\end{array}$ & $\begin{array}{r}0.428 \\
0.182 \\
0.084 \\
-0.057 \\
37.337 \\
42.648\end{array}$ & $\begin{array}{l}\star \\
\star \\
\star \\
\star\end{array}$ \\
\hline GLZ - centre only & 0.71 & 30.3 & $\star \star \star$ & NA & NA & $\begin{array}{l}\text { Intercept } \\
\text { Axis } \\
\text { Mean TS } \\
\text { Mean TSS } \\
\text { Min TSS } \\
\text { Max SM }\end{array}$ & $\begin{array}{r}0.260 \\
-0.067 \\
0.159 \\
0.082 \\
-0.109 \\
62.398\end{array}$ & * \\
\hline SAR - centre only & 0.88 & 28.95 & * & Binary & 450 & $\begin{array}{l}\text { Intercept } \\
\text { Axis } \\
\text { Mean TS } \\
\text { Mean TSS } \\
\text { Min TSS } \\
\text { Max SM }\end{array}$ & $\begin{array}{r}0.213 \\
-0.073 \\
0.175 \\
0.071 \\
-0.102 \\
64.632\end{array}$ & $\begin{array}{l}\star \\
\star\end{array}$ \\
\hline GLZ - crack only & 0.61 & 28.2 & $\star \star \star$ & NA & NA & $\begin{array}{l}\text { Intercept } \\
\text { Snow } \\
\text { Min TS } \\
\text { Min SM } \\
\text { Max SM }\end{array}$ & $\begin{array}{r}1.681 \\
0.488 \\
0.063 \\
33.540 \\
13.888\end{array}$ & $\begin{array}{l}\star \\
\star\end{array}$ \\
\hline SAR - crack only & 0.83 & 18.96 & $\star$ & Row-standardized & 450 & $\begin{array}{l}\text { Intercept } \\
\text { Snow } \\
\text { Min TS } \\
\text { Min SM } \\
\text { Max SM }\end{array}$ & $\begin{array}{r}1.636 \\
0.420 \\
0.067 \\
28.604 \\
16.520\end{array}$ & $\begin{array}{l}\star \\
\star \\
\star \\
\star \\
\star\end{array}$ \\
\hline
\end{tabular}

$\star \star \star P P 0.001,{ }^{\star} P<0.05$. Adj. $R^{2}$, coefficient of determination, adjusted to account for differences in the number of parameters in the models; Pseudo- $R^{2}, R^{2}$-equivalent for SAR models; Axis, maximum diameter of the polygon in metres; Snow, presence or absence of snow; TS, surface temperature; TSS, sub-surface temperature; SM, soil moisture in grams of water per gram of soil; NA, not applicable.

Table 2. Repeated random sub-sampling validation of best-fitting of generalized linear (GLZ) models and spatially explicit simultaneous autoregressive (SAR) models

\begin{tabular}{llcc}
\hline Model type & & GLZ & SAR \\
\hline$R^{2}$ & Full & 0.845 & 0.910 \\
& Training $^{\dagger}$ & 0.859 & 0.835 \\
& Test $^{\dagger}$ & 0.819 & 0.813 \\
\hline
\end{tabular}

${ }^{\dagger}$ Mean of 1000 repeats.

variance, with the best single predictor for GLZ and SAR models being maximum soil moisture, which explained between $78 \%$ and $81 \%$ of the variance in the mite abundance data (Fig. 3; Table 3).

(C) 2012 The Authors

Austral Ecology (C) 2012 Ecological Society of Australia

\section{DISCUSSION}

Using straightforward, spatially explicit environmental and abundance data, simultaneous auto-regressive models for the full dataset explained $92 \%$ of the variation in the abundance of $M$. wilsoni across the polygonal soil environment. The environmental parameter with the greatest explanatory power was maximum soil moisture, which is strongly related to the presence of M. wilsoni in the moister polygon cracks. This is contrary to findings of Barrett et al. (2004) who determined that at sites in the McMurdo Dry Valleys, polygon centres contained the highest abundance and biodiversity despite being drier than polygon cracks. 
Table 3. Spatially non-explicit generalized linear (GLZ) models and spatially explicit simultaneous autoregressive (SAR) models for single predictors, ranked by adjusted $R^{2}$ and pseudo- $R^{2}$ respectively

\begin{tabular}{|c|c|c|c|c|c|c|c|}
\hline & Predictor & Adj $R^{2} /$ Pseudo- $R^{2}$ & $\begin{array}{l}\text { Likelihood ratio } \\
\text { test statistic }\end{array}$ & $P$ & $\begin{array}{l}\text { Neighbourhood } \\
\text { Distance (m) }\end{array}$ & Coefficient & $P$ \\
\hline \multirow[t]{12}{*}{ SAR } & Max SM & 0.81 & 54.17 & $\star \star \star$ & 300 & 47.61 & $\star \star \star$ \\
\hline & Mean SM & 0.80 & 57.08 & $\star \star \star$ & 300 & 72.416 & $\star \star \star$ \\
\hline & Min SM & 0.69 & 36.95 & $\star \star \star$ & 300 & 153.492 & $\star \star \star$ \\
\hline & Snow & 0.44 & 7.54 & $\star \star \star$ & 75 & 0.534 & $\star \star \star$ \\
\hline & Location & 0.70 & 40.33 & $\star \star \star$ & 75 & 1.572 & $\star \star \star$ \\
\hline & Max TS & 0.32 & 2.39 & 0.122 & 75 & -0.047 & 0.112 \\
\hline & Mean TS & 0.28 & 0.37 & 0.541 & 75 & -0.027 & 0.540 \\
\hline & Min TS & 0.32 & 1.33 & 0.249 & 75 & 0.042 & 0.207 \\
\hline & Max TSS & 0.37 & 5.63 & $\star$ & 75 & -0.098 & $\star$ \\
\hline & Mean TSS & 0.34 & 4.95 & $\star$ & 75 & -0.120 & $\star$ \\
\hline & Min TSS & 0.29 & 1.57 & 0.210 & 75 & -0.052 & 0.205 \\
\hline & Axis length & 0.27 & 0.00 & 0.951 & 75 & -0.002 & 0.951 \\
\hline \multirow[t]{12}{*}{ GLZ } & Max SM & 0.78 & 61.265 & $\star \star \star$ & NA & 49.395 & $\star \star \star$ \\
\hline & Mean SM & 0.72 & 52.015 & $\star \star \star$ & NA & 72.906 & $\star \star$ \\
\hline & Min SM & 0.51 & 29.775 & $\star \star \star$ & NA & 132.227 & $\star \star$ \\
\hline & Snow & 0.05 & 2.936 & 0.087 & NA & 0.509 & 0.097 \\
\hline & Location & 0.66 & 44.333 & $\star \star \star$ & NA & 1.567 & $\star \star \star$ \\
\hline & Max TS & 0.00 & 1.135 & 0.287 & NA & -0.043 & 0.302 \\
\hline & Mean TS & -0.01 & 0.557 & 0.456 & NA & -0.044 & 0.470 \\
\hline & Min TS & 0.01 & 1.406 & 0.236 & NA & -0.066 & 0.251 \\
\hline & Max TSS & 0.08 & 4.313 & $\star$ & NA & -0.116 & $\star$ \\
\hline & Mean TSS & 0.10 & 5.178 & $\star$ & NA & -0.158 & $\star$ \\
\hline & Min TSS & -0.02 & 0.086 & 0.770 & NA & -0.014 & 0.777 \\
\hline & Axis length & -0.03 & 0.021 & 0.886 & NA & 0.008 & 0.889 \\
\hline
\end{tabular}

Neighbourhood weighting method for all SAR models is binary. ${ }^{\star \star \star} P<0.001,{ }^{\star} P<0.05$. 'Location' denotes whether the sample was from a crack or a centre habitat and all other abbreviations are as in Table 1. Axis, maximum diameter of the polygon in metres; Snow, presence or absence of snow; TS, surface temperature; TSS, sub-surface temperature; SM, soil moisture in grams of water per gram of soil; NA, not applicable.

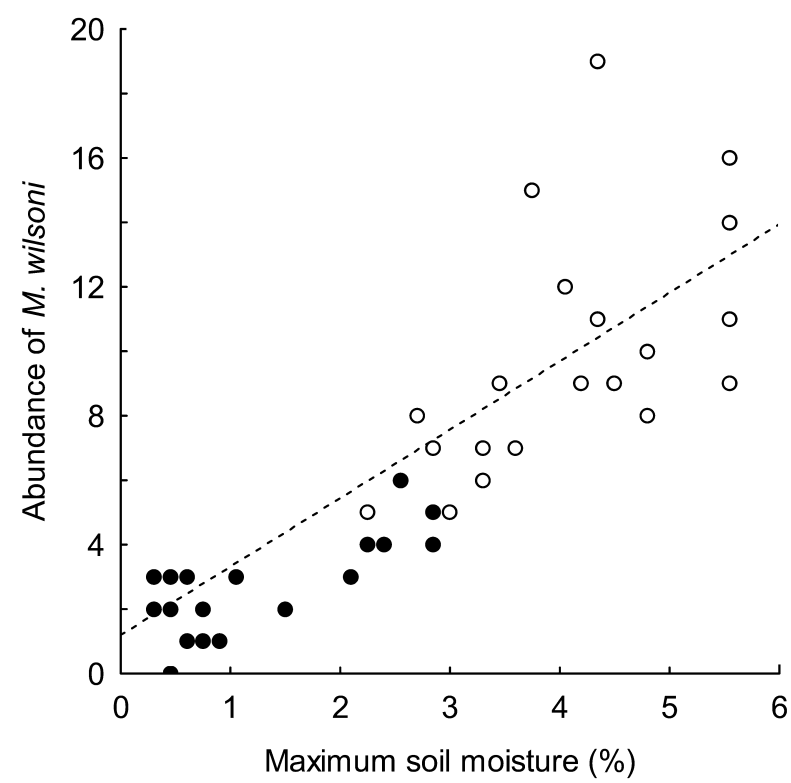

Fig. 3. The relationship between maximum soil moisture and the abundance of Maudheimia wilsoni. Open symbols represent polygon crack habitats, closed symbols represent centre habitats.
However, in this case the dominant organisms were nematodes rather than arthropods, suggesting that factors other than soil moisture, such as frost-related soil activity in the cracks, may take primacy in determining abundance in this group.

The high proportion of variance explained by models in our study differs from temperate systems where correlative models typically have much lower explanatory power and even the best models only explain between about 50\% (e.g. Brewer \& Gaston 2002) and about $70 \%$ (McGeoch \& Price 2004) of variation in abundance. On sub-Antarctic Heard Island, where biotic interactions (specifically competition and predation) are likely to be intermediate between temperate and Antarctic systems, Davies et al. (2011) successfully explained $81 \%$ of the variation in the abundance of the weevil Bothrometopus brevis (although percentage variation explained for other species on this island was much lower, ranging between 23\% and 62\%; see Appendix S3 in Supporting Information). In continental Antarctic systems, studies that relate organism abundance to directly measured environmental variables typically do not report the degree of variance explained (see Appen-

(C) 2012 The Authors

Austral Ecology (C) 2012 Ecological Society of Australia 
dix S3 in Supporting Information for examples of studies which do so). However, an investigation of abundance variation in the springtails Cryptopygus cisantarcticus, Isotoma klovstadi and Friesea grisea at Cape Hallett found that $>80 \%$ of the variation in abundance could be explained by correlative models (Sinclair et al. 2006). In consequence, the approach applied here may hold much promise for the region and should be explored further. Although water availability is acknowledged to take primacy in determining patterns of biodiversity in Antarctic landscapes, the shape of response curves for other taxa, particularly those able to endure anhydrobiosis, may vary (Adams et al. 2006; Brinkmann et al. 2007) and additional investigations would be required before community level forecasts could be made.

The small difference in $R^{2}$ values between the training and test datasets (Table 2) indicates that the best-fit model in this study is able to successfully predict arthropod abundance at a polygonal soil landscape-scale at the Jutulsessen site. Given the increased fitness of many arthropods in high moisture environments as a result of higher survival and increased availability of food resources (Convey et al. 2003), and the strong co-variance in plant and animal distributions (Peck et al. 2006; Sinclair et al. 2006; Ayres et al. 2010), if other taxa are shown to have similar response curves, correlative species distribution models which utilize soil moisture data may prove useful in identifying high biodiversity sites in other stress-dominated continental Antarctic systems. Use of species distribution models to identify these sites could prove to be an important conservation tool, as systematic conservation planning in Antarctica is currently constrained by the lack of spatially explicit biodiversity data, particularly from remote continental sites (Hughes \& Convey 2010). Because many of these sites are difficult to access, and conducting such biodiversity assessments requires considerable logistic support and access to taxonomic expertise, the ability to optimize sampling strategies to capture a high proportion of biodiversity is important. Predictive models of the kind shown here could facilitate such optimization.

The high proportion of variance explained by the GLZ models is also important because, at least when predicting species occurrences, these models are often found to be least effective in so doing (Austin 2007; Santika \& Hutchinson 2009) and therefore are often overlooked as a useful modelling approach. One reason for their poor performance is their assumptions of linear relationships when the relationship between the environmental variable of interest and species performance is often non-linear, such as in the case of various environmental response curves
(Austin 2007; Chown \& Gaston 2008). Here, strong linear relationships were found between soil moisture and mite abundance, which likely reflects both linearly increasing algal food resources (Bokhorst et al. 2007; although see Brinkmann et al. 2007) and improved mite survival (see also Marshall 1996). Although the full response curve, both for the resource and for desiccation resistance of the mite, may be approximately Gaussian (see Chown \& Gaston 2008), it seems likely that at the low water contents here $(<1 \%$ to $6 \%$ by comparison with temperate soils which typically have water contents an order of magnitude higher; Nijssen et al. 2001), the right-hand decline in the response curve is veiled, so making a linear model appropriate. Even if this portion of the response curve is unveiled in other circumstances, alternative modelling techniques could readily capture the non-linearities (see Santika \& Hutchinson 2009; Caruso et al. 2010). Nonetheless, fairly linear responses to conditions in the absence of strong biotic interactions have also been found in much moister environments in the broader Antarctic region (see, e.g. Lee et al. 2009; Davies et al. 2011). Perhaps the main limitation of this approach in 'island-like' Antarctic systems is that it is not able to account for stochasticity associated with past and future colonization events (see discussion in, e.g. Adams et al. 2006; Convey et al. 2008). However, the predictive modelling approach used here may prove to be much more useful than the existing literature suggests as it provides a readily accessible means of filtering out areas which are currently unsuitable for biota and identifying those which merit further, on-the-ground investigation.

The utility of species distribution models to forecast biodiversity over wider spatial scales and predict how it may change in the future is limited by the capability of current remote-sensing techniques to measure the necessary model parameters (in this case soil moisture) or their proxies at a sufficiently fine spatial scale (Guisan \& Thuiller 2005). A potentially useful source of remotely sensed soil moisture data is the European Space Agency Soil Moisture and Ocean Salinity (SMOS) satellite that was launched in November 2009 to observe soil moisture over the Earth's landmasses and salinity over the oceans. The SMOS's Microwave Imaging Radiometer with Aperture Synthesis captures images of emitted microwave radiation around the frequency of $1.4 \mathrm{GHz}$ (L-band) and a range of surface characteristics, including soil moisture, soil surface roughness and texture, land cover, surface heterogeneity, dew, snow, topography, litter effect and surface water, are inferred. A major limitation of SMOS is the large pixel size, with the spatial resolution at the centre of the field of view being only $35 \mathrm{~km}$ (Azcurra \& Walker 2009), meaning 
it is unable to detect moist microsites at ecologically relevant scales for Antarctica's fauna. However, increasing resolution of similar instruments is likely to develop rapidly through sensor modification or deployment on aircraft, which will prove useful for future forecasting.

In the interim, an alternative approach would be the identification of areas of moisture heterogeneity, such as periglacial patterned ground features like soil polygons, from existing general survey data where available or from high-resolution satellite images (using existing data sources such as QuickBird (http://www.satimagingcorp.com) and Landsat (http://landsat.gsfc.nasa.gov) ) for unexplored areas. Although location in the polygon habitat (i.e. crack or centre) explained slightly less of the variation in $M$. wilsoni abundance than soil moisture in univariate models (Table 3), when location and snow are used as predictors, model performance improves considerably $\left(R^{2}=0.77\right.$, likelihood ratio $=54.02$, $P<0.0001)$. As both these parameters can be detected from satellite images (see Appendix S1 in Supporting Information), this may prove a powerful combination of variables. Furthermore, because polygonal soil landscapes are typically only formed in snow-free conditions, and because in Antarctica the dominant freeze-thaw cycle is seasonal, not diurnal, ice wedge polygons large enough to detect from satellite images are likely to develop on a time scale of thousands of years (Murton 2007). Therefore, using satellite imagery to select sites with patterned ground features as targets for future biodiversity surveys is optimal not only because it provides an indication of the moisture heterogeneity, but also because it provides some indication of the glacial history of the site and thus the time for which it has been exposed and available for colonization via long distance dispersal (Marshall \& Chalmers 1997; Nkem et al. 2006). Although sites that have been exposed for prolonged periods may not necessarily have been colonized (e.g. Dufek Massif; Hodgson et al. 2010), presence of well-developed periglacial landscape features does provide an indication of colonization potential.

In conclusion, in low-interaction systems such as the Antarctic, on small spatial scales straightforward, correlative models can be used to accurately forecast patterns of mite abundance. Further research is needed to determine if such models could be used to predict variation in the abundance of taxa with different life forms and habitat requirements and if high predictive ability is retained at larger spatial scales. At a regional scale in Victoria Land, abundance and distribution of biota, particularly those with low dispersal capabilities such as arthropods, appear to be only weakly related to broad latitudinal or altitudinal gradients and instead are characterized by local 'hotspots' and non-linear patterns (Caruso et al. 2010). However, incorporation of landscape features that act as proxies for microclimatic variation into regional scale models may be a relatively simple way to improve the predictive ability of these models. Given the forecast environmental change in the Antarctic region, validation of spatially explicit correlative models for other taxa, other regions and across larger scales should be a conservation priority. Better understanding of the spatial distribution of biodiversity is necessary to provide a baseline for detecting, monitoring and predicting the impacts of climate change (Turner et al. 2009) and introduced species (Frenot et al. 2005) on biota and ecosystem processes. If models, such as used here, are valid at a regional scale they may provide useful information as to where to target biodiversity surveys. These data are vital in developing the strategic conservation framework required by the Antarctic Treaty (see Hughes \& Convey 2010). The coupling of remote sensing methods and models of the kind validated here can provide a cost-effective method for optimizing the provision of such biodiversity data (see also Fretwell \& Trathan 2009).

\section{ACKNOWLEDGEMENTS}

Bernard Coetzee provided useful comments on a previous version of this manuscript and Louise Coetzee provides taxonomic advice. The South African National Antarctic Programme and Norwegian Polar Institute are thanked for logistic support during fieldwork. This work was supported partly by the British Antarctic Survey and partly by SANAP grants SNA200704200003 and SNA2005061300001.

\section{REFERENCES}

Adams B. J., Bardgett R. D., Ayres E. et al. (2006) Diversity and distribution of Victoria Land biota. Soil Biol. Biochem. 38, 3003-18.

Austin M. (2007) Species distribution models and ecological theory: a critical assessment and some possible new approaches. Ecol. Modell. 200, 1-19.

Ayres E., Nkem J. N., Wall D. H. et al. (2010) Experimentally increased snow accumulation alters soil moisture and animal community structure in a polar desert. Polar Biol. 33, 897-907.

Azcurra C. \& Walker J. P. (2009) Towards SMOS validation in south-eastern Australia. In: 18th World IMACS Congress and MODSIM09 International Congress on Modelling and Simulation (eds R. S. Anderssen, R. D. Braddock \& L. T. H. Newham) pp. 3675-81. Modelling and Simulation Society of Australia and New Zealand and International Association for Mathematics and Computers in Simulation, Cairns.

(C) 2012 The Authors
Austral Ecology (C) 2012 Ecological Society of Australia 
Ballantyne C. K. (2007) Patterned ground. In: Encyclopedia of Quaternary Science (ed. S. A. Elias) pp. 2182-91. Elsevier, Missouri.

Barrett J. E., Virginia R. A., Wall D. H., Parsons A. N., Powers L. E. \& Burkins M. B. (2004) Variation in biogeochemistry and soil biodiversity across spatial scales in a polar desert ecosystem. Ecology 85, 3105-18.

Beale C. M., Lennon J. J., Yearsley J. M., Brewer M. J. \& Elston D. A. (2010) Regression analysis of spatial data. Ecol. Lett. $13,246-64$.

Bockheim J. G. \& Hall K. J. (2002) Permafrost, active-layer dynamics and periglacial environments of continental Antarctica. S. Afr. F. Sci. 98, 82-90.

Bokhorst S., Ronfort C., Huiskes A., Convey P. \& Aerts R. (2007) Food choice of Antarctic soil arthropods clarified by stable isotope signatures. Polar Biol. 30, 983-90.

Brewer A. M. \& Gaston K. J. (2002) The geographical range structure of the holly leaf-miner. 1. Population density. 7. Anim. Ecol. 71, 99-111.

Brinkmann M., Pearce D. A., Convey P. \& Ott S. (2007) The cyanobacterial community of polygon soils at an inland Antarctic nunatak. Polar Biol. 30, 1505-11.

Caruso T., Hogg I. D. \& Bargagli R. (2010) Identifying appropriate sampling and modelling approaches for analysing distributional patterns of Antarctic terrestrial arthropods along the Victoria Land latitudinal gradient. Antarct. Sci. 22, $742-8$.

Chown S. L. \& Gaston K. J. (2008) Macrophysiology for a changing world. Proc. R. Soc. B. 275, 1469-78.

Chown S. L., Hoffmann A. A., Kristensen T. N., Angilletta M. J., Stenseth N. C. \& Pertoldi C. (2010) Adapting to climate change: a perspective from evolutionary physiology. Clim. Res. 43, 3-15.

Convey P., Block W. \& Peat H. J. (2003) Soil arthropods as indicators of water stress in Antarctic terrestrial habitats? Glob. Chang. Biol. 9, 1718-30.

Convey P., Gibson J. A. E., Hillenbrand C. D. et al. (2008) Antarctic terrestrial life - challenging the history of the frozen continent? Biol. Rev. 83, 103-17.

Davies K. F., Melbourne B. A., McClenahan J. L. \& Tuff T. (2011) Statistical models for monitoring and predicting effects of climate change and invasion on the free-living insects and a spider from sub-Antarctic Heard Island. Polar Biol. 34, 19-125.

Dennett D. (1996) Darwin's Dangerous Idea - Evolution and the Meanings of Life. Touchstone, New York.

Dormann C. F., McPherson J. M., Araujo M. B. et al. (2007) Methods to account for spatial autocorrelation in the analysis of species distributional data: a review. Ecography 30, 609-28.

Elith J. \& Leathwick J. R. (2009) Species distribution models: ecological explanation and prediction across space and time. Annu. Rev. Ecol. Evol. Syst. 40, 677-97.

French H. M. \& Guglielmin M. (2000) Frozen ground phenomena in the vicinity of Terra Nova Bay, Northern Victoria Land, Antarctica: a preliminary report. Geogr. Ann. A. 82A, 513-26.

Frenot Y., Chown S. L., Whinam J. et al. (2005) Biological invasions in the Antarctic: extent, impacts and implications. Biol. Rev. 80, 45-72.

Fretwell P.T. \& Trathan P. N. (2009) Penguins from space: faecal stains reveal the location of emperor penguin colonies. Glob. Ecol. Biogeogr. 18, 543-52.

Gaston K. J. (2000) Global patterns in biodiversity. Nature 405, $220-7$.
Guisan A. \& Thuiller W. (2005) Predicting species distribution: offering more than simple habitat models. Ecol. Lett. 8, 993-1009.

Hodgson D. A., Convey P., Verleyen E. et al. (2010) The limnology and biology of the Dufek Massif, Transantarctic Mountains $82^{\circ}$ South. Polar Sci. 4, 197-214.

Hogg I. D., Cary S. C., Convey P. et al. (2006) Biotic interactions in Antarctic terrestrial ecosystems: are they a factor? Soil Biol. Biochem. 38, 3035-40.

Hughes K. A. \& Convey P. (2010) The protection of Antarctic terrestrial ecosystems from inter- and intra-continental transfer of non-indigenous species by human activities: a review of current systems and practices. Glob. Environ. Change 20, 96-112.

Janetschek H. (1970) Environments and ecology of terrestrial arthropods in the high Antarctic. In: Antarctic Ecology, Vol. 2. (ed. M. W. Holdgate) pp. 871-85. Academic Press, London.

Kearney M. \& Porter W. (2009) Mechanistic niche modelling: combining physiological and spatial data to predict species' ranges. Ecol. Lett. 12, 334-50.

Kearney M., Porter W. P., Williams C., Ritchie S. \& Hoffmann A. A. (2009) Integrating biophysical models and evolutionary theory to predict climatic impacts on species' ranges: the dengue mosquito Aedes aegypti in Australia. Funct. Ecol. 3, 528-38.

Kissling W. D. \& Carl G. (2008) Spatial autocorrelation and the selection of simultaneous autoregressive models. Glob. Ecol. Biogeogr. 17, 59-71.

Kozak K. H. \& Wiens J. J. (2007) Climatic zonation drives latitudinal variation in speciation mechanisms. Proc. R. Soc. B. 274, 2995-3003.

Lavergne S., Muenke N. J. \& Molofsky J. (2010) Genome size reduction can trigger rapid phenotypic evolution in invasive plants. Ann. Bot. 105, 109-16.

Lawton J. H. (1999) Are there general laws in ecology? Oikos 84, 177-92.

Lee J. E., Janion C., Marais E., Vuuren B. J. \& Chown S. L. (2009) Physiological tolerances account for range limits and abundance structure in an invasive slug. Proc. R. Soc. B. 276, 1459-68.

Marshall D. J. (1996) Comparative water relations of subAntarctic and continental Antarctic oribatid mites. Polar Biol. 16, 287-92.

Marshall W. A. \& Chalmers M. O. (1997) Airborne dispersal of Antarctic terrestrial algae and cyanobacteria. Ecography 2, 585-94.

May R. M. (1986) The search for patterns in the balance of nature: advances and retreats. Ecology 67, 1115-26.

McGeoch M. A. \& Price P. W. (2004) Spatial abundance structures in an assemblage of gall-forming sawflies. F. Anim. Ecol. 73, 506-16.

Millennium Ecosystem Assessment (2005) Ecosystems and Human Well-Being: Biodiversity Synthesis. World Resources Institute, Washington, DC.

Murton J. (2007) Ice wedges and ice wedge casts. In: Encyclopedia of Quaternary Science (ed. S. A. Elias) pp. 2153-70. Elsevier, Amsterdam.

Nijssen B., Schnur R. \& Lettenmaier P. (2001) Global retrospective estimation of soil moisture using the variable infiltration capacity land surface model, 1980-93. F. Clim. 14, 1790808.

Nkem J., Wall D., Virginia R. et al. (2006) Wind dispersal of soil invertebrates in the McMurdo Dry Valleys, Antarctica. Polar Biol. 29, 346-52. 
Pearson R. G. \& Dawson T. P. (2003) Predicting the impacts of climate change on the distribution of species: are bioclimate envelope models useful? Glob. Ecol. Biogeogr. 12, 36171

Peck L. S., Convey P. \& Barnes D. K. A. (2006) Environmental constraints on life histories in Antarctic ecosystems: tempos, timings and predictability. Biol. Rev. 81, 75-109.

Porter W. P., Budaraju S., Stewart W. E. \& Ramankutty N. (2000) Calculating climate effects on birds and mammals: impacts on biodiversity, conservation, population parameters, and global community structure. Am. Zool. 40, 597630.

Pugh P. J. A. (1993) A synonymic catalogue of the Acari from Antarctica, the sub-Antarctic islands and the SouthernOcean. F. Nat. Hist. 27, 323-421.

Quinn G. P. \& Keough M. J. (2002) Experimental Design and Data Analysis for Biologists. Cambridge University Press, Cambridge.

R Development Core Team (2010) R: A Language and Environment for Statistical Computing. R Foundation for Statistical Computing, Vienna.

Reijmer C. H. \& van den Broeke M. R. (2001) Moisture precipitation in Western Dronning Maud Land, Antarctica. Antarct. Sci. 13, 210-20.

Santika T. \& Hutchinson M. F. (2009) The effect of species response form on species distribution model prediction and inference. Ecol. Modell. 220, 2365-79.

Sinclair B. J., Scott M. B., Klok C. J. et al. (2006) Determinants of terrestrial arthropod community composition at Cape Hallett, Antarctica. Antarct. Sci. 18, 303-12.

Soberón J. (2007) Grinnellian and Eltonian niches and geographic distributions of species. Ecol. Lett. 10, 111523.
Sohlenius B. \& Boström S. (2008) Species diversity and random distribution of microfauna in extreamly isolated habitable patches on Antarctic nunataks. Polar Biol. 31, 81725.

Thuiller W. (2007) Biodiversity: climate change and the ecologist. Nature 448, 550-2.

Thuiller W., Richardson D. M., Pysek P., Midgley G. F., Hughes G. O. \& Rouget M. (2005) Niche-based modelling as a tool for predicting the risk of alien plant invasions at a global scale. Glob. Chang. Biol. 11, 2234-50.

Turner J., Bindschadler R. A. \& Convey P. et al., eds (2009) Antarctic Climate Change and the Environment. Scientific Committee on Antarctic Research, Cambridge.

Woodward F. I. \& Kelly C. K. (2008) Responses of global plant diversity capacity to changes in carbon dioxide concentration and climate. Ecol. Lett. 11, 1229-37.

Zar J. H. (1984) Biostatistical Analysis, 2nd edn. Prentice-Hall, London.

\section{SUPPORTING INFORMATION}

Additional Supporting Information may be found in the online version of this article:

Appendix S1. Satellite image showing soil polygon landscape at Jutulsessen nunatak.

Appendix S2. Soil moisture meter calibration.

Appendix S3. Examples of other linear model studies in the Antarctic and sub-Antarctic. 